\title{
KUALITAS HIDUP SIBLING ANAK DENGAN AUTIS
}

\author{
Ikeu Nurhidayah ${ }^{1}$, Sri Hendrawati ${ }^{2}$, Yuli Anggia ${ }^{3}$ \\ Universitas Padjadjaran ${ }^{1,2,3}$ \\ sri.hendrawati@unpad.ac.id ${ }^{2}$
}

\begin{abstract}
ABSTRAK
Penelitian ini bertujuan untuk mengidentifikasi gambaran kualitas hidup sibling anak dengan autis. Desain penelitian menggunakan metode deskriptif kuantitatif. Hasil penelitian menunjukkan sebanyak 17 orang $(51,51 \%)$ termasuk kategori baik, sementara sebanyak 16 orang $(48,48 \%)$ termasuk kategori buruk. Terdapat dua dimensi kualitas hidup yang masih termasuk kedalam kategori buruk yaitu dimensi emosi dan dimensi sekolah. Simpulan, kualitas hidup akan berpengaruh terhadap tumbuh kembang sibling, sehingga upaya yang dapat dilakukan untuk mempertahankan dan meningkatkan kualitas hidup sibling anak dengan autis adalah melalui pendidikan kesehatan kepada sibling terkait cara menghadapi kondisi anak dengan autis dan kepada keluarga terkait pentingnya dukungan sosial bagi sibling anak dengan autis.
\end{abstract}

Kata Kunci: Autis, Kualitas hidup, Sibling

\section{ABSTRACT}

This study aims to identify the quality of life picture of sibling children with autism. The research design uses quantitative descriptive methods. The results showed as many as 17 people (51.51\%) included in the first category, while as many as 16 people (48.48\%) were included in the wrong category. There are two dimensions of quality of life that are still involved in the wrong group, namely the emotional aspect and the school dimension. Conclusion, quality of life will affect sibling growth and development so that efforts can be made to maintain and improve the quality of life of sibling children with autism through health education to sibling related to how to deal with the condition of children with autism and to families regarding the importance of social support for sibling children with autistic.

Keywords: Autism, Quality of life, Sibling

\section{PENDAHULUAN}

Masa anak dianggap sebagai fase yang penting karena akan menentukan kualitas kesehatan, kesejahteraan, pembelajaran, dan perilaku dimasa yang akan datang serta masa depan masyarakat tergantung pada anak-anak yang mampu mencapai pertumbuhan dan perkembangan yang optimal (Padila et al., 2019; Panzilion et al., 2020; WHO, 2017).

Pada masa ini terjadi perkembangan fisik, psikomotorik, hubungan sosial, dan perkembangan kepribadian. Kehadiran anak merupakan saat yang dinantikan oleh orang tua (Wahyu et al., 2018). Anak yang terlahir sehat dan sempurna merupakan harapan semua orang tua. Tentunya setiap orang tua menginginkan anaknya terlahir normal 
dalam keadaan sempurna. Namun dalam realitanya tidak semua anak terlahir dalam keadaan sempurna, setiap anak memiliki kelebihan dan kekurangan. Tidak semua orang tua dapat menerima keadaan anaknya yang memiliki kekurangan serta mampu tumbuh dan berkembang dengan baik seperti yang diharapkan orang tua (Sujito, 2017). Banyak faktor yang memengaruhi proses perkembangan anak, baik yang bersifat internal maupun eksternal. Terdapat beberapa gangguan yang dialami oleh anak dalam proses berkembang, sehingga dapat menghambat proses perkembangannya. Salah satu gangguan perkembangan yang terjadi adalah autis. Autis merupakan gangguan perkembangan yang dapat terjadi sejak bayi atau balita yang dapat menyebabkan anak tidak mampu membentuk hubungan dan berinteraksi dengan dunia luar yang dapat ditandai dengan adanya keterlambatan dalam kognitif, bahasa, perilaku, komunikasi, dan interaksi sosial (Yanti, 2017).

Angka kejadian autis di dunia saat ini terus meningkat. Autis dapat terjadi pada semua kondisi, terjadi di seluruh bangsa, ras dan semua tingkat sosial. Autis seringkali ditemukan lebih banyak pada anak laki-laki, terjadi 3-4 kali dibandingkan anak perempuan. Data Autism Speaks (2018) menunjukkan bahwa 1 dari 59 anak terdiagnosis mengalami autis. Terjadi peningkatan sebanyak 15\% dari tahun 2012. Di Indonesia, autis merupakan salah satu gangguan perkembangan yang menjadi sorotan. Angka kejadian autis di Indonesia mengalami peningkatan yang cukup pesat. Diperkirakan terdapat lebih dari 134.000 anak yang menderita autis dalam rentang usia 5-19 tahun pada tahun 2015 (Naibaho et al., 2017).

Menurut data Institute for Health Metrics and Evaluation (2017) sebanyak 0,85\% dari total populasi mengalami autis. Jumlah anak autis yang tercatat di Dinas Pendidikan Jawa Barat sebanyak 1.524 anak. Jumlah terbanyak terdapat di Kabupaten dan Kota Bandung, yaitu mencapai 35\% dari total anak autis yang terdapat di Jawa Barat. Gangguan spektrum autis dapat dilihat dari keterbatasan anak dalam interaksi sosial, komunikasi baik verbal maupun nonverbal, dan keterbatasan aktivitas yang dapat terlihat pada periode perkembangan awal (Pangestu, Fibriana, 2017; Yanti, 2017).

Kehadiran anak berkebutuhan khusus seperti autis, membutuhkan seseorang untuk membantu memenuhi kebutuhannya akibat keterbatasan yang ia miliki. Dalam hal ini, keluarga merupakan orang terdekat yang akan menjalankan peran tersebut. Namun, keluarga juga mempunyai peran lain selain menjaga dan merawat anak dengan autis, sehingga kondisi ini dapat menyebabkan caregiver burden (Fithria, Yusri, 2016). Penelitian yang dilakukan oleh Chodidjah, Kusumasari (2018) menunjukkan hasil bahwa terjadinya stres pada orang tua selama merawat anaknya yang mengalami autis. Orang tua mengalami stres emosional, mengkhawatirkan hubungan anaknya yang mengalami autis dengan anaknya yang lain, mengkhawatirkan masa depan anak yang mengalami autis, mengkhawatirkan pendidikan anak, dan harus menghadapi masalah terkait finansial.

Kehadiran anak dengan autis juga akan berdampak terhadap kehidupan sibling atau saudara kandungnya (Blankenship, 2016). Sibling anak dengan autis seringkali mengalami perbedaan dalam hal perhatian orang tua dan memiliki tanggung jawab ekstra dalam membantu orang tua untuk merawat saudaranya. Sibling anak dengan autis harus menyesuaikan diri dengan kondisi saudara mereka yang memerlukan perhatian khusus, dukungan sosial dan psikologis yang lebih besar, serta memerlukan sebagian besar waktu keluarga. Memiliki saudara berkebutuhan khusus dapat memberikan tantangan emosional dan perilaku bagi saudaranya yang lain (Aytekin, 2016). Kehadiran anak dengan autis dapat menunjukkan perasaan yang berubah-ubah serta memberikan 
dampak positif maupun dampak negatif bagi sibling. Respon yang ditimbulkan akan beragam (Chodidjah, Kusumasari, 2018).

Penelitian yang dilakukan oleh Naibaho et al., (2017) terhadap remaja yang mempunyai saudara kandung dengan autis, menunjukkan hasil bahwa 30\% remaja memiliki hubungan interaksi yang kurang dengan saudara mereka yang mengalami autis. Seringkali mereka memilih untuk tidak menjalin interaksi. Beberapa perilaku yang ditunjukkan oleh sibling anak dengan autis adalah merasa cemburu dengan perlakuan orang tua dan sering bertengkar. Ada masanya sibling anak dengan autis akan merasakan marah dan tidak bisa mengerti dengan tingkah laku saudaranya yang autis. Pada beberapa kondisi, sibling anak dengan autis belum bisa menerima saudaranya yang dianggap berbeda dengan dia dan teman-temannya. Proses interaksi dengan anak autis akan mengalami kesulitan yang lebih untuk mendapatkan respon timbal balik dibandingkan dengan anak normal. Berdasarkan hasil penelitian Braconnier et al., (2018) sibling anak dengan autis dapat mengalami depresi dan kekhawatiran yang lebih tinggi terhadap saudara kandungnya dibandingkan orang tuanya. Tetapi selain itu dalam penelitian ini juga disebutkan, sibling juga cenderung mengambil peran pengasuhan dan dapat dilibatkan dalam melakukan intervensi pada anak autis.

Kondisi yang ditemukan pada sibling khususnya di wilayah Bandung, menunjukkan respon yang beragam terkait kehadiran anak dengan autis. Sebagian sibling menunjukkan perasaan senang dan tetap berinteraksi serta bermain bersama dengan saudaranya yang mengalami autis, namun sebagiannya lagi menunjukkan tingkat interaksi yang lebih rendah. Sibling juga merasakan perasaan cemburu terhadap perhatian orang tua, salah satu contohnya adalah terkait waktu yang dihabiskan oleh orang tua lebih banyak dengan anak dengan autis. Selain itu, beberapa sibling mengambil peran yang lebih besar dari usia seharusnya. Sebuah penelitian yang dilakukan oleh Naibaho et al., (2017) menemukan bahwa hubungan saudara kandung yang terbentuk antara remaja dengan saudaranya yang memiliki autis di salah satu Yayasan Autisme di Kota Bandung menunjukkan hasil yang negatif. Padahal hubungan saudara kandung ini memberikan pengaruh terhadap beberapa aspek kualitas hidup, seperti perkembangan emosional, interaksi sosial dan terkait rasa nyaman.

Penting bagi perawat untuk mengetahui kualitas hidup anak, khususnya sibling anak dengan autis untuk memberikan asuhan keperawatan guna mempertahankan dan meningkatkan derajat kesehatannya. Saat ini, penelitian terkait kualitas hidup sibling anak dengan autis di Indonesia masih belum banyak ditemukan, sehingga perlu dilakukan penelitian ini dengan harapan dapat menjadi salah satu bahan masukan khususnya untuk keilmuan keperawatan dalam menentukan intervensi yang tepat sesuai dengan kondisi kesehatan anak, khususnya sibling anak dengan autis. Penelitian ini bertujuan untuk mengidentifikasi gambaran kualitas hidup sibling anak dengan autis, khususnya di wilayah Bandung.

\section{METODE PENELITIAN}

Rancangan penelitian yang digunakan dalam penelitian ini adalah deskriptif kuantitatif. Penelitian ini mengidentifikasi kualitas hidup sibling anak dengan autis. Populasi dalam penelitian ini adalah sibling anak dengan autis yang berusia 8-18 tahun di yayasan dan sekolah autis di wilayah Bandung sebanyak 33 orang. Teknik pengambilan sampel yang digunakan dalam penelitian ini yaitu total sampling. Penelitian ini dilakukan lebih kurang selama 2 bulan terhitung dari bulan Februari 2019 hingga April 2019. Penelitian ini dilakukan di Yayasan Autisma Prananda, Yayasan 
Risantya, SLB Yapmi, SLB Negeri Cileunyi, SLB Solalin, dan SLB Multahada yang berada di wilayah Kota Bandung dan Kabupaten Bandung

Alat pengumpulan data yang digunakan dalam penelitian ini adalah kuesioner. Kuesioner yang digunakan terdiri dari data demografi dan pertanyaan untuk menilai kualitas hidup anak. Pada penelitian ini kualitas hidup diukur menggunakan instrumen baku yang dirancang oleh Dr. James W. Varni sejak tahun 1998 yaitu Instrumen PedsQLTM 4.0 Generic Core Scales Child Report. Instrumen PedsQLTM 4.0 Generic Core Scales Child Report sudah diuji validitas dan reliabilitasnya serta sudah dialih bahasakan ke dalam bahasa Indonesia. Instrumen inimemiliki nilai reliabilitas 0,835 . Kuesioner ini terdiri dari 23 butir pertanyaan yang dibagi kedalam empat sub penilaian. Kualitas hidup anak dinilai melalui empat dimensi, yaitu dimensi fisik, emosi, sosial dan sekolah. Pada penelitian ini kuesioner diisi oleh anak yaitu sibling anak dengan autis. Hal ini bertujuan agar nilai yang didapatkan lebih representatif karena sesuai dengan laporan anak secara langsung terkait kondisi yang ia rasakan. Kuesioner ini menggunakan skala likert dari 0-4 dengan penjelasan 0 tidak pernah, 1 hampir tidak pernah, 2 kadang-kadang, 3 sering, 4 hampir selalu. Setiap skor yang diisi ditransformasi ke skala 0-100 $(0=100,1=75,2=50,3=25,4=0)$.

Pengambilan data dilakukan langsung kepada sibling anak dengan autis dengan mengunjungi rumah dengan meminta izin dan ketersediaan orang tua terlebih dahulu. Peneliti melakukan informed consent kepada orang tua dan sibling. Menjelaskan maksud dan tujuan peneliti serta meminta kesediaan sibling untuk menjadi responden tanpa unsur pemaksaan. Penelitian ini menggunakan analisis univariat untuk menggambarkan kualitas hidup sibling anak dengan autis menggunakan mean atau ratarata, standar deviasi, dan frekuensi serta pengolahan data dilakukan melalui aplikasi statistik. Data digambarkan dalam bentuk distribusi frekuensi dan persentase. Kualitas hidup dikategorikan baik apabila nilai skor total $\geq$ nilai mean dan dikategorikan buruk apabila nilai skor total < nilai mean.

Penelitian ini telah mendapatkan pembebasan etik dari Komite Etik Penelitian Universitas Padjadjaran dengan No.215/UN6.KEP/EC/2019 pada tanggal 26 Februari 2019. Prinsip-prinsip etik yang akan diterapkan oleh peneliti diantaranya, menghormati harkat dan martabat manusia (Respect for human dignity), menghormati privasi dari subjek penelitian (Respect for privacy), memberikan keadilan (Respect for justice), serta memperhitungkan manfaat dan kerugian (Balancing harms and benefits)

\section{HASIL PENELITIAN}

Tabel. 1

Distribusi Frekuensi Karakteristik Demografi Sibling Anak Autis $(\mathrm{n}=33)$

\begin{tabular}{llcc}
\hline No. & Karakteristik Responden & Frekuensi $(f)$ & Persentase \\
\hline 1. & Jenis Kelamin & 20 & \\
& Laki-Laki & 13 & $60,60 \%$ \\
& Perempuan & & $39,39 \%$ \\
\hline 2. & Usia & 16 & $48,48 \%$ \\
& 8-12 Tahun & 17 & $51,51 \%$ \\
\hline 3. & 13-18 Tahun & & \\
& Posisi dalam Hubungan Saudara Kandung & 13 & $39,39 \%$ \\
& Kakak & 20 & $60,60 \%$
\end{tabular}




\begin{tabular}{lcc}
\hline $4 . \quad$ Jumlah Saudara Kandung & & \\
$\quad>3$ Orang & 0 & $0,00 \%$ \\
$\leq 3$ Orang & 33 & $100,00 \%$ \\
\hline
\end{tabular}

Sumber Data: Yayasan dan Sekolah Autis di Wilayah Bandung

Pada tabel 1 diketahui bahwa dari 33 orang sibling anak dengan autis di wilayah Bandung, mayoritas berjenis kelamin laki-laki, berusia 13-18 tahun, merupakan seorang adik dari anak dengan autis, dan jumlah saudara kandungnya $\leq 3$ orang. Sebanyak 20 orang $(60,60 \%)$ berjenis kelamin laki-laki dan 13 orang $(39,39 \%)$ berjenis kelamin perempuan. Termasuk dalam kategori usia 8-12 tahun sebanyak 16 orang $(48,48 \%)$ dan kategori usia 13-18 tahun sebanyak 17 orang (51,51\%). Posisi dalam hubungan saudara kandung, terdiri dari 13 orang (39,39\%) sebagai kakak dari anak dengan autis dan 20 orang $(60,60 \%)$ yang berkedudukan sebagai adik dari anak dengan autis. Semua responden $(100 \%)$ mempunyai saudara kandung $\leq 3$ orang.

Tabel. 2

Nilai Rata-rata, Standar Deviasi, Nilai Minimal dan Nilai Maksimal

Kualitas Hidup Sibling Anak Autis (n=33)

\begin{tabular}{cccccc}
\hline No. & Kategori & Rata-rata & SD & Min & Max \\
\hline 1. & Kualitas Hidup Total & 80,37 & 13,79 & 42,94 & 100 \\
2. & Kesehatan Fisik & 84,28 & 16,30 & 25,00 & 100 \\
& Dimensi Fisik & 84,28 & 16,30 & 25,00 & 100 \\
3. & Kesehatan Psikososial & 76,56 & 15,25 & 35,88 & 100 \\
& Dimensi Emosi & 72,87 & 17,27 & 30,00 & 100 \\
& Dimensi Sosial & 81,81 & 22,38 & 25,00 & 100 \\
& Dimensi Sekolah & 74,69 & 13,16 & 50,00 & 100 \\
\hline
\end{tabular}

Sumber Data: Yayasan dan Sekolah Autis di Wilayah Bandung

Pada tabel 2 menunjukkan bahwa nilai rata-rata kualitas hidup sibling anak dengan autis di wilayah Bandung adalah sebesar 80,37 dengan standar deviasi 13,79. Untuk kesehatan fisik menunjukkan nilai rata-rata sebesar 84,28 dengan standar deviasi 16,30. Sementara untuk kesehatan psikososial yang diperoleh dari tiga dimensi, yaitu dimensi emosi, dimensi sosial dan dimensi sekolah, menunjukkan nilai rata-rata sebesar 76,56 dengan standar deviasi 15,25 . Untuk dimensi emosi diketahui nilai rata-rata sebesar 72,87 dengan standar deviasi 17,27; dimensi sosial diketahui nilai rata-rata sebesar 81,81 dengan standar deviasi 22,38; dan dimensi sekolah diketahui nilai rata-rata sebesar 74,69 dengan standar deviasi 13,16. Berdasarkan hasil tersebut diketahui bahwa dimensi fisik dan dimensi sosial memiliki nilai rata-rata $\geq 80,37$. Sementara dimensi emosi dan dimensi sekolah memiliki nilai rata-rata $<80,37$.

Tabel. 3

Distribusi Frekuensi Kualitas Hidup Sibling Anak Autis ( $\mathrm{n}=33)$

\begin{tabular}{cccc}
\hline No. & Kategori & Frekuensi $(f)$ & Persentase \\
\hline 1. & Kualitas Hidup Total & 17 & $51,51 \%$ \\
& Baik & 16 & $48,48 \%$ \\
& Buruk & & \\
2. & Kesehatan Fisik & & \\
& - Dimensi Fisik & 19 & $57,57 \%$ \\
& Baik & 14 & $42,42 \%$ \\
\hline
\end{tabular}




\begin{tabular}{ccc}
\hline 3. & & \\
Kesehatan Psikososial & 16 & $48,48 \%$ \\
Baik & 17 & $51,51 \%$ \\
Buruk & 13 & $39,39 \%$ \\
- Dimensi Emosi & 20 & $60,60 \%$ \\
Baik & & \\
Buruk & 18 & $54,54 \%$ \\
- Dimensi Sosial & 15 & $45,45 \%$ \\
Baik & & $30,31 \%$ \\
Buruk & 10 & $69,69 \%$ \\
- Dimensi Sekolah & 23 & \\
Baik & & \\
Buruk &
\end{tabular}

Sumber Data: Yayasan dan Sekolah Autis di Wilayah Bandung

Pada tabel 3 menunjukkan bahwa sibling anak dengan autis di wilayah Bandung sebagian besar mempunyai kualitas hidup baik sebanyak 17 orang $(51,51 \%)$. Untuk kesehatan fisik yang diperoleh dari nilai rata-rata pada dimensi fisik menunjukkan sebagian besar berada pada kategori baik sebanyak 19 orang $(57,57 \%)$. Sementara untuk kesehatan psikososial yang diperoleh dari nilai rata-rata tiga dimensi yaitu, dimensi emosi, dimensi sosial, dan dimensi sekolah, sebagian besar berada pada kategori buruk sebanyak 17 orang $(51,51 \%)$.

\section{PEMBAHASAN}

Hasil penelitian terkait kualitas hidup sibling anak dengan autis di wilayah Bandung menunjukkan nilai rata-rata untuk kualitas hidup adalah 80,37. Hasil tersebut dapat dikatakan bahwa nilai untuk kualitas hidup sibling anak dengan autis di wilayah Bandung merupakan nilai yang cukup tinggi yang menandakan bahwa mayoritas sibling anak dengan autis di wilayah Bandung termasuk ke dalam kategori kualitas hidup baik. Namun hanya selisih satu angka dengan jumlah sibling yang termasuk kedalam kategori buruk. Sehingga kondisi ini menjadi riskan dan tetap perlu menjadi perhatian untuk kedepannya.

Terdapat beberapa kemungkinan faktor yang dapat memengaruhi kualitas hidup sibling anak dengan autis yaitu kemampuan penyesuaian diri, dukungan sosial yang diterima, pola asuh, serta strategi koping yang dimiliki oleh sibling. Dalam penelitian ini, terdapat dua kategori usia sibling yaitu usia sekolah dan usia remaja. Kualitas hidup yang baik lebih banyak ditunjukkan oleh sibling yang termasuk dalam kategori usia sekolah. Hal ini mungkin dapat disebabkan karena pada usia ini sibling berada pada fase belajar mengembangkan sikap positif, baik terhadap dirinya maupun dalam kehidupan sosial (Khasanah et al., 2019).

Dari hasil penelitian, meskipun mayoritas sibling anak dengan autis mempunyai kualitas hidup yang baik tetapi jika dilihat dari setiap dimensi kualitas hidup, terdapat dimensi yang mempunyai nilai dibawah rata-rata total atau termasuk kedalam kategori buruk yaitu dimensi emosi dan dimensi sekolah. Kondisi ini dapat berdampak terhadap proses perkembangan dan konsep diri sibling apabila tidak diatasi dengan cepat.

Sama halnya dengan penelitian Pattynama, Pandia (2016) di Jakarta yang menyebutkan bahwa sibling anak dengan autis pada umumnya memiliki kualitas hidup yang baik, tetapi tidak dalam dimensi aktivitas bersama dan penerimaan lingkungan. Faktor yang mempengaruhi kualitas hidup ini diantaranya pola asuh, tingkat kecacatan, nilai-nilai, dan status ekonomi keluarga. Namun, sibling mengalami ketidakpuasan terhadap perlakuan dari orang tuanya. Sibling merasa diperlakukan tidak sama oleh 
ibunya, seperti perlakuan kepada saudaranya yang autis, dan merasa orang tua tidak memahami dirinya. Selain itu, sibling juga cenderung pendiam ketika berada di rumah, tetapi lebih ceria ketika berada di lingkungan luar rumah dengan teman sebayanya. Penelitian McKechanie et al., (2017) juga menunjukkan hasil bahwa kualitas hidup sibling anak dengan autis tidak terganggu. Hal ini disebabkan karena sibling mampu menyesuaikan diri dengan kondisi saudara mereka yang mengalami autis. Sibling tidak mengeluh dan menganggap situasi mereka sebagai hal yang normal dan tidak menyulitkan. Selain itu sibling juga mendapatkan dukungan sosial yang dari orang tua dan teman sebaya sehingga sibling tidak merasa kesepian, serta sibling dan orang tua mempunyai strategi koping yang baik dalam menghadapi berbagai masalah.

Berbeda dengan penelitian yang dilakukan oleh Esfahani et al., (2018) di Tehran, yang meneliti kualitas hidup sibling anak dengan autis dan sibling anak dengan penyakit fisik kronis. Penelitian ini menunjukkan hasil bahwa kualitas hidup sibling anak dengan autis lebih rendah dibandingkan dengan sibling anak dengan penyakit fisik kronis. Salah satu faktor yang dapat menyebabkan rendahnya kualitas hidup sibling anak dengan autis dibandingkan dengan sibling anak dengan penyakit fisik kronis adalah terkait dengan sindrom autistik pada saudara mereka, seperti hambatan dalam bersosialisasi, berkomunikasi dan berperilaku. Selain itu, sibling dengan anak autis memiliki berbagai masalah psikologis dan masalah sosial yang dapat berpengaruh terhadap kehidupan sehari-hari, seperti menjadi lebih cemas dengan kondisi saudaranya dan berperilaku lebih agresif.

Dimensi fisik merupakan dimensi yang menunjukkan nilai paling tinggi berdasarkan hasil penelitian yaitu dengan rata-rata 84,28. Mayoritas responden menunjukkan kualitas hidup baik yaitu sebanyak 19 orang $(57,57 \%)$. Kemungkinan yang dapat memengaruhinya adalah kondisi fisik sibling yang sehat serta tidak memiliki penyakit lain. Sehingga dimensi fisik ini harus di maintenance agar tidak terjadi penurunan yang dapat berdampak pada kemampuan sibling melakukan aktivitas seharihari. Hasil penelitian ini sejalan dengan penelitian Lovell, Wetherell (2016) yang menyatakan bahwa fungsi fisik pada sibling anak dengan autis tidak mengalami masalah.

Berbeda dengan penelitian sebelumnya yang dilakukan oleh Gona et al., (2016) yang meyebutkan bahwa dimensi fisik pada orang tua terganggu, begitupun dimensi fisik pada sibling anak dengan autis pun terganggu karena mengalami kelelahan akibat ikut serta dalam merawat saudaranya yang autis dan ikut serta membantu orang tua menyelesaikan pekerjaan rumah. Sementara hal demikian tidak ditemukan pada sibling anak autis di wilayah Bandung. Hanya saja sibling pernah merasa sakit atau terluka. Hal ini dirasakannya saat anak dengan autis mengalami tantrum. Sehingga kondisi ini berimplikasi bahwa perlu adanya tambahan informasi dari perawat untuk sibling dan orang tua terkait cara menghadapi anak dengan autis saat mengalami tantrum dan berperilaku agresif agar dapat terhindar dari sakit atau risiko cedera.

Dimensi emosi merupakan dimensi yang menunjukkan nilai terendah dibandingkan dimensi lainnya yaitu dengan rata-rata 72,87. Mayoritas responden menunjukkan kualitas hidup buruk yaitu sebanyak 20 orang $(60,60 \%)$. Rata-rata pada dimensi emosi akan berpengaruh pada kesehatan psikososial sibling. Nilai pada dimensi emosi, dimensi sosial dan dimensi sekolah akan berbanding lurus dengan kesehatan psikologisnya. Semakin bagus nilai pada setiap dimensi maka kesehatan psikososial akan semakin baik dan sebaliknya. Berdasarkan rata-rata jawaban sibling pada dimensi 
emosi menunjukkan bahwa sibling merasa marah $(67,42)$, takut dan khawatir tentang apa yang akan terjadi pada mereka $(69,69)$.

Dalam hal ini, keluarga mempunyai peran penting dalam meningkatkan kondisi kesehatan sibling. Orang tua perlu mengetahui bahwa ia harus fairness kepada anakanaknya, memberikan penjelasan kepada sibling terkait kondisi anak dengan autis sejak kecil supaya sibling mampu memahami kondisinya saat ini, serta orang tua perlu menyediakan waktu luang khusus untuk berdiskusi dengan sibling agar ia tetap merasakan perhatian serta dukungan emosional dari orang tuanya. Permasalahan terkait dimensi emosi ini akan berdampak pada kesehatan psikososial jika tidak segera diatasi.

Kemungkinan faktor yang dapat memengaruhi dimensi emosi sibling adalah dukungan sosial dan emosional yang diterima serta strategi kopingnya. Pada dimensi emosi ini, mayoritas sibling yang termasuk kedalam kategori buruk adalah yang termasuk usia remaja. Usia remaja merupakan masa peralihan yang merupakan periode mencari identitas diri. terjadi perubahan pada emosi, minat dan juga perilaku. Sehingga hal ini mungkin juga menjadi salah satu faktor yang menyebabkan masalah yang berkaitan dengan dimensi emosi sibling anak dengan autis. Pada usia ini terjadi kematangan kognitif, yaitu sudah mampu memikirkan bahwa apa yang dilakukan saat ini dapat berpengaruh terhadap masa depan. Dalam hal ini mungkin saja sibling sudah memikirkan masa depan dirinya dan juga saudaranya yang mengalami autis, sehingga menimbulkan kekhawatiran terhadap apa yang akan terjadi.

Penelitian Lovell, Wetherell (2016) juga menyebutkan bahwa sibling anak dengan autis dilaporkan memiliki peningkatan dalam masalah perilaku dan emosional yang bahkan sampai menimbulkan gejala depresi. Sibling merasakan kekhawatiran tentang masa depan, merasa marah, dan malu dengan kondisi saudara mereka yang mengalami autis. Dukungan sosial terutama dari orang tua dan teman dekat diharapkan dapat menurunkan gejala depresi pada sibling. Namun berbeda halnya dengan penelitian Chan, Lai (2016) yang dilakukan di Hongkong yang menunjukkan hasil bahwa tidak terdapat masalah perilaku dan emosional yang negatif secara signifikan pada sibling dengan anak autis.

Dimensi sosial merupakan dimensi yang mempunyai nilai tertinggi kedua setelah dimensi fisik. Mayoritas responden menunjukkan kualitas hidup baik yaitu sebanyak 18 orang $(54,54 \%)$. Kemungkinan faktor yang dapat memengaruhi dimensi sosial sibling adalah dukungan sosial yang berarti, perilaku serta kebutuhan anak dengan autis serta penerimaan lingkungan. Beberapa kemungkinan faktor tersebut dapat memengaruhi persepsi sibling terhadap kualitas hidupnya.

Pada dimensi sosial, mayoritas sibling yang termasuk kedalam kategori baik adalah yang tergolong usia sekolah dan usia remaja. Usia sekolah merupakan periode anak dalam pemantapan hubungan sosial dengan lingkungan. Pada usia remaja anak sudah mencapai hubungan yang matang dengan teman sebaya. Sehingga hasil penelitian ini menggambarkan bahwa sibling menunjukkan proses perkembangan yang sesuai dengan usianya. Kondisi ini perlu di maintenance agar dapat berdampak positif terhadap kondisi kesehatan psikososial sibling dan proses perkembangannya. Berbeda dengan penelitian yang dilakukan oleh Tomeny et al., (2017) yang menyebutkan bahwa terjadi disfungsi perilaku dan hubungan sosial yang rendah pada sibling anak dengan autis. Selaras dengan penelitian yang dilakukan Chan, Lai (2016) di Hongkong yang menunjukkan hasil bahwa sibling menunjukkan hubungan dengan teman sebaya dan perilaku prososial yang lemah. 
Dimensi sekolah merupakan dimensi terendah kedua dari empat dimensi yang dinilai. Mayoritas responden menunjukkan kualitas hidup buruk yaitu sebanyak 23 orang $(69,69 \%)$. Pada dimensi sekolah, mayoritas sibling adalah termasuk kedalam usia remaja. Seharusnya pada tahap ini terjadi perkembangan kognitif, meliputi belajar, menalar, berfikir, bahasa dan daya ingat atau memori.

Kemungkinan faktor yang dapat memengaruhi pada dimensi sekolah adalah kondisi emosional sibling yang terganggu. Berbagai gangguan pada dimensi sekolah ini dapat berdampak pada kesuksesan anak di sekolah apabila tidak segera diatasi. Dimensi sekolah ini erat kaitannya dengan perkembangan kognitif. Hal ini sejalan dengan penelitian Latifa (2017) yang menyebutkan bahwa perkembangan kognitif salah satunya dapat dipengaruhi dan memengaruhi aspek perkembangan emosional. Selain itu, sibling anak dengan autis menunjukkan kemampuan kognitif yang lebih rendah dibandingkan dengan sibling yang tidak mempunyai saudara autis.

\section{SIMPULAN}

Hasil penelitian ini menunjukkan bahwa kualitas hidup sibling anak dengan autis di wilayah Bandung, sebagian besar dari responden berada pada kategori kualitas hidup baik dan hampir setengahnya responden berada pada kategori kualitas hidup buruk. Dimensi fisik merupakan dimensi dengan nilai rata-rata tertinggi, sementara dimensi emosi merupakan dimensi dengan nilai rata-rata paling rendah. Meskipun hasil penelitian menunjukkan bahwa lebih dari setengah dari responden termasuk dalam kategori kualitas hidup baik, terdapat dua dimensi kualitas hidup yang termasuk dalam kategori buruk yaitu dimensi emosi dan dimensi sekolah. Rendahnya nilai pada kedua dimensi tersebut, berdampak pada rendahnya kesehatan psikososial sibling anak autis di wilayah Bandung.

\section{SARAN}

Dalam hal ini, keluarga merupakan bagian terdekat dari sibling sehingga peneliti menyarankan bahwa orang tua dapat memberikan dukungan emosional kepada sibling anak dengan autis dengan menyediakan waktu luang maupun memberikan perhatian yang sama kepada anak-anaknya. Serta memberikan informasi terkait kondisi yang dapat dialami oleh anak dengan autis yang dapat berpengaruh kepada sibling, sehingga sibling mampu memahami dan menyesuaikan diri dengan kondisi tersebut. Kualitas hidup akan berpengaruh terhadap tumbuh kembang sibling, sehingga upaya yang dapat dilakukan untuk mempertahankan dan meningkatkan kualitas hidup sibling anak dengan autis adalah melalui pendidikan kesehatan kepada sibling terkait cara menghadapi kondisi anak dengan autis dan kepada keluarga terkait pentingnya dukungan sosial bagi sibling anak dengan autis.

\section{DAFTAR PUSTAKA}

Autism Speaks. (2018). CDC Increases Estimate of Autism's Prevalence by 15 Percent, to 1 in 59 Children | Autism Speaks. In Autism Speaks

Aytekin, C. (2016). Siblings of Disabled Children: A General Overview in terms of Academic Studies. International Journal of Innovation and Applied Studies, 16(3), 522-527

Blankenship, J. (2016). Autism as an Ambiguous Loss: The Experience of Multiple Family Members. Dissertation Abstracts International: Section B: The Sciences and Engineering, 76(9-B(E)) 
Braconnier, M. L., Coffman, M. C., Kelso, N., \& Wolf, J. M. (2018). Sibling Relationships: Parent-Child Agreement and Contributions of Siblings with and Without ASD. Journal of Autism and Developmental Disorders, 48(5), 16121622. https://doi.org/10.1007/s10803-017-3393-9

Chan, J. Y., \& Lai, K. Y. (2016). Psychological Adjustment of Siblings of Children with Autism Spectrum Disorder in Hong Kong. East Asian Archives of Psychiatry, 26(4), 141-147

Chodidjah, S., \& Kusumasari, A. P. (2018). Pengalaman Ibu Merawat Anak Usia Sekolah dengan Autis. Jurnal Keperawatan Indonesia, 21(2), 94-100. https://doi.org/10.7454/jki.v21i2.545

Esfahani, F. N., Shooshtari, M. H., Sosfadi, R. S., Saeed, F., Jalai, F., Farsham, A., \& Bidaki, R. (2018). Internalizing and Externalizing Problems, Empathy Quotient, and Systemizing Quotient in 4 to 11 Years-Old Siblings of Children with Autistic Spectrum Disorder Compared to Control Group. Iranian Journal of Psychiatry, 13(3), 192-200

Fithria, F., \& Yusri, Y. (2016). Caregiver Burden pada Keluarga dengan Anak Berkebutuhan. Jurnal Ilmiah Mahasiswa Fakultas Keperawatan, 1(1), 1-5

Gona, J. K., Newton, C. R., Rimba, K. K., Mapenzi, R., Kihara, M., Vijver, F. V, \& Abubakar, A. (2016). Challenges and Coping Strategies of Parents of Children with Autism on the Kenyan Coast. Rural Remote Health, 16(2), 1-15. https://doi.org/10.1002/andp.18742261215

Institute for Health Metrics and Evaluation. (2017). Global Burden of Disease Study 2016 (GBD 2016) Results. In Global Burden of Disease Collaborative Network (Vol. 2016, Issue Gbd 2016)

Khasanah, U. A., \& Indrayati, N. (2019). Hubungan Perkembangan Psikososial dengan Prestasi Belajar Anak Usia Sekolah. Jurnal Ilmu Keperawatan Jiwa, 2(3), 157. https://doi.org/10.32584/jikj.v2i3.426

Latifa, U. (2017). Aspek Perkembangan pada Anak Sekolah Dasar: Masalah dan Perkembangannya. Journal of Multidisciplinary Studies, 1(2), 185-196

Lovell, B., \& Wetherell, M. (2016). The Psychophysiological Impact of Childhood Autism Spectrum Disorder on Siblings. Research in Developmental Disabilities, 49-50, 226-234. https://doi.org/https://doi.org/10.1016/j.ridd.2015.11.023

McKechanie, A., Moffat, V., Johnstone, E., \& Fletcher-Watson, S. (2017). Links between Autism Spectrum Disorder Diagnostic Status and Family Quality of Life. Children, 4(4), 23. https://doi.org/10.3390/children4040023

Naibaho, S. T., Victoriana, E., \& Tjoeng, N. T. (2017). Studi Deskriptif mengenai Sibling Relationship pada Remaja dengan Saudara Spektrum Autisme. Humanitas (Jurnal Psikologi), 1(2), 103. https://doi.org/10.28932/humanitas.v1i2.419

Padila, P., Andari, F. N., \& Andri, J. (2019). Hasil Skrining Perkembangan Anak Usia Toddler antara DDST dengan SDIDTK. Jurnal Keperawatan Silampari, 3(1), 244-256. https://doi.org/10.31539/jks.v3i1.809

Pangestu, N., \& Fibriana, A. I. (2017). Faktor Risiko Kejadian Autisme. Higeia Journal of Public Health Research and Development, 1(2), 141-150

Panzilion, P., Padila, P., Amin, M., \& Andri, J. (2020). Perkembangan Motorik Prasekolah antara Intervensi Brain Gym dengan Puzzle. Jurnal Keperawatan Silampari, 3(2), 510-519. https://doi.org/https://doi.org/10.31539/jks.v3i2.1120 
Pattynama, P. C., \& Pandia, W. S. S. (2016). Gambaran Kualitas Hidup Saudara Kandung Penyandang Autism Spectrum Disorder (Penelitian pada Remaja Akhir di Jakarta). Jurnal Pekotaan, 8(1), 1-11

Sujito, E. (2017). Dinamika Penerimaan Orangtua yang Memiliki Anak Berkebutuhan Khusus. Skripsi

Tomeny, T. S., Barry, T. D., \& Fair, E. C. (2017). Parentification of Adult Siblings of Individuals with Autism Spectrum Disorder: Distress, Sibling Relationship Attitudes, and the Role of Social Support. Journal of Intellectual \& Developmental Disability, 42(4). https://doi.org/https://doi.org/10.3109/13668250.2016.1248376

Wahyu, H., Betrianita, B., Pramesti, M. T., \& Padila, P. (2018). Pengaruh Metode Glenn Doman (Tahap 1 dan 2) terhadap Perkembangan Komunikasi Anak Autisme di Autis Center Bengkulu. Jurnal Keperawatan Silampari, 2(1), 169-183. https://doi.org/10.31539/jks.v2i1.306

WHO. (2017). Early Child Development. https://www.tandfonline.com/loi/gecd20?open=187\&year=2017\&repitition=0\#vol 187_2017

Yanti, R. D. (2017). Studi Fenomenologi Pengalaman Koping Remaja yang Memiliki Saudara Kandung dengan Autisme di Sekolah Luar Biasa Kota Padang. Jurnal Akademika Baiturrahim, 6(1), 17-25 